\title{
Expansión ultramarina y economía vitivinícola. El ejemplo de Canarias (1500-1550)
}

\author{
Overseas expansion of a viticulture economy. \\ The case of the Canary Islands (1500-1550)
}

\author{
ANTONIO M. MACÍAS HERNÁNDEZ \\ Universidad de La Laguna
}

\begin{abstract}
RESUMEN
La colonización de Canarias a finales del siglo XV motivó la génesis y el posterior desarrollo de la primera vitivinicultura insular y atlántica forjada por la expansión ultramarina de la Corona de Castilla. En poco más de veinte años, esta nueva vitivinicultura abasteció el mercado interior y accedió a los mercados del noroeste europeo y al creado por la expansión colonial de los reinos ibéricos. Este artículo examina las estrategias que motivaron esta nueva y competitiva

vitivinicultura, e insiste en el papel desempeñado por el factor institucional y por una cultura colonizadora lusa y castellana que arribó a las islas con el decidido propósito de construir una economía vitivinícola vinculada al mercado internacional. ABSTRACT

The colonization of the Canary Islands at the end of the 15th century induced the foundation and growth of the first insular and Atlantic viticulture, promoted by the ultramarine expansion of the Corona of Castile. In little more than twenty years, the new producers were supplying both the domestic and the Northwest European markets, as well as the new ones created by the colonial expansion of the Iberian Kingdoms. This article examines the strategies that encouraged the development of this new and competitive viticulture, and insists on the role played by institutional factors as well as by the Portuguese and Castilian colonial determination of developing, at the Canary Islands, a wine production tied to the international market.
\end{abstract}

PALABRAS CLAVE: Economía vitivinícola, Colonización agraria, Expansión europea, España, siglo XVI Códigos JEL: Q17

KEY WORDS: Viticulture, European expansion, Agrarian colonization, Spain, 16th century

JEL Codes: Q17 


\section{Introducción ${ }^{1}$}

$\mathrm{L}$

a colonización de Canarias bajo la Corona de Castilla con el apoyo del capital mercantil comenzó en el último cuarto del siglo $\mathrm{XV}$, y su fuerza motriz fue la agroindustria azucarera. El sostenido crecimiento de esta agroindustria, vinculada a los mercados del Mediterráneo y del noroeste europeo, atrajo hombres y capitales, y forjó una economía que demandó crecientes importaciones de bienes de equipo, manufacturados y agropecuarios.

El vino se encontraba entre estos bienes, pero pronto surgió una vitivinicultura con fuerza y calidad en sus elaboraciones. Así, en 1507, el viajero Valentín Fernández cita la excelencia de los vinos de Gran Canaria y la abundancia de los de Tenerife², cuya primera vendimia se puso a la venta en 1501. La expansión vitivinícola siguió su curso y la calidad acompañó a la abundancia según la autoridad local de Tenerife que, en 1516, afirmaba que sus vinos "son buenos y no con horruras y turbios, lo que es en contrario los vinos de Castilla, que hasta Navidad están turbios y con madres y horruras, que es cosa muy dañosa" ${ }^{\prime 3}$. Finalmente, hacia 1520, la oferta vinícola de Tenerife y La Palma accedió a los mercados indiano y europeo, y la economía vitivinícola mantuvo su predominio en la estructura productiva del archipiélago hasta mediados del siglo XIX ${ }^{4}$.

El presente artículo analiza la construcción de esta primera economía vitivinícola de la expansión ultramarina de Castilla. Una economía que surgió de la nada e interesa, por tanto, examinar la política de los delegados regios en los repartos de tierras para vides con el fin de aclarar el papel institucional en esta distribución y la estructura de la propiedad nacida de estos repartos. En este sentido, como se examina en el segundo apartado, la estrategia de plantar cepas para cubrir el consumo familiar preponderó entre los colonos que carecían del capital necesario para participar en la economía azucarera en calidad, al menos, de cañavereros. Pero esta estrategia no explica el triunfo de un esfuerzo tecnológico que exigió la pronta adaptación del quehacer vitivinícola europeo a su nuevo solar atlántico. Por consiguiente, cabe sostener que el colonato vitivinicultor arribó a las islas con el propósito de construir una economía vitivinícola vinculada al mercado. Se requiere, entonces, precisar el origen de este colonato y las razones de su inmigración, entre las que, de nuevo, encontramos el factor institucional.

[Fecha de recepción del original, junio de 2006. Versión definitiva, diciembre de 2006]

Agradezco sus sugerencias a los avaluadores anónimos de Investigaciones de Historia Económica.

Magalhaes (1982), p. 244.

Serra y Rosa (1965), p. 181.

Macías (2000). 
Los apartados tercero y cuarto tratan sobre la formación del mercado vinícola en un territorio de nueva colonización. En ellos se estudian la magnitud del consumo y la demanda interior, con objeto de comprobar su papel en la génesis y desarrollo vitivinícola y la respuesta de los productores. La carencia de asientos contables se ha resuelto mediante un modelo hipotético de explotación, elaborado a partir de diversas fuentes; aunque los datos son poco rigurosos y difíciles de contrastar debido a la inexistencia de estudios sobre otros territorios insulares de colonización vitivinícola, permiten conocer las decisiones de inversión del colonato vitivinicultor y el momento en que éste se planteó con fundamento competitivo su acceso al mercado internacional. El quinto apartado se refiere a este mercado; examina la liberalización de las exportaciones vinícolas y sus principales destinos, al objeto de precisar la importancia de una demanda que determinará toda la historia posterior de la economía vitivinícola isleña.

\section{La política colonizadora vitivinícola}

La primera viña insular y atlántica se plantó en Gran Canaria a mediados del siglo XIV. Luego, en la siguiente centuria, los colonos del señorío de Canarias hicieron nuevos plantíos en las islas que lograron arrebatar al poder indígena (Lanzarote, Fuerteventura, La Gomera y El Hierro), pero no desarrollaron una economía vitivinícola vinculada al mercado. En realidad, ésta sólo inició su andadura a partir de la conquista y colonización de Gran Canaria (1478-1482), La Palma (1494) y Tenerife (1496), y tuvo como primer incentivo un factor institucional favorable al proceso colonizador.

El interés geopolítico presidió la política de la Corona. Su objetivo era establecer una economía de servicios marítimos vinculada a sus proyectos africanista y americano. Debía entonces afianzar su dominio sobre el territorio, acallando así la vieja querencia de su homónima lusa, y el único modo de lograrlo consistía en priorizar el poblamiento del archipiélago. De ahí que ordenara a sus gobernadores que procedieran de inmediato a repartir de manera gratuita las tierras y las aguas entre el colonato, sin reparar en su origen, y que otorgara a éste exenciones fiscales y plena libertad mercantil 5 .

5 Gran Canaria disfrutó de exención fiscal por veinte años (1487-1507), abonando únicamente el diezmo y un derecho aduanero del 3 por 100 ad valorem, que subió al 5 por 100 en 1507 a cambio de la exención fiscal a perpetuidad. La colonización de Tenerife y La Palma comenzó en 1496, y su colonato obtuvo total exención hasta 1522. La uniformidad tributaria llegó en 1522; en 1528 se incrementó el derecho aduanero al 6 por 100 y en 1543 se fijó un arancel de salida del 2,5 por 100 sobre el comercio indiano. 
Las Canarias carecían del principal móvil de la expansión europea, los metales preciosos. Su única riqueza era la tierra y de ella debía obtenerse el producto exportador que financiara la colonización, sufragara las importaciones y generara a medio plazo el ahorro-inversión necesario para asegurar el éxito de la nueva economía ${ }^{6}$. Y como determinados espacios ofrecían condiciones favorables a la agroindustria azucarera, cuya exportación alcanzaba elevadísimos precios, los delegados regios repartieron las tierras y las aguas con la expresa obligación de destinar ambos recursos a los cañaverales. Pero debían también asegurar el abastecimiento de vino, un bien imprescindible en la dieta de una población que crecía al ritmo acelerado de los cañaverales. El medio más eficaz era promover la vitivinicultura. Además, existía tierra libre y fértil para este objeto. Los cañaverales ocuparon una pequeña franja del territorio y las condiciones edáficas de la mayor parte de sus suelos — soleados y bien drenados por su naturaleza volcánica- sugieren que su verdadera vocación era la viticultura.

\subsection{El predominio de la pequeña propiedad}

Los repartidores otorgaron mercedes con la obligación de plantar vides en las laderas que rodeaban las vegas de caña y en las proximidades de los centros "urbanos". Y aunque todos los colonos podían acceder a estas concesiones, la mayor parte recayó en los que carecían del capital necesario para participar en la economía azucarera. El colono debía roturar la merced y levantar en ella casa poblada en un plazo de cinco años. Esta medida, tendente a fijar la población y cumplir con el objetivo regio, se vio complementada por otra cuyo fin era promover el viñedo mediante la creación de pequeñas haciendas; una estrategia en la cesión de la tierra que, por otra parte, era propia de la estructura agraria vitícola del período moderno.

Los colonos recibieron una merced de tierra libre de toda carga de una superficie en torno a las cinco fanegadas (2,62 hectáreas), donde debían edificar su vivienda y un majuelo cercado para evitar los daños del ganado ${ }^{7}$. Esta obligación, denominada

\footnotetext{
Macías (2001).

Serra (1978). Data a Juan Ortega de Bega, de probable origen lusitano (10/04/1504): “una suerte en Tacoronte que fue de Juan Cansado, portugués, más las 8 fanegadas de tierra que yo vos di por vecindad en el Arautava, que son para una casa y viña" (p. 50, data 174). Data a Fernán González, portugués (12/08/1506): “vos doy en... Icoden 6 fanegadas de riego..., junto con Roy Blas [portugués], en que fagais una viña,... con un sitio para facer una casa... porque queréis venir a vivir con vuestra mujer e hijos" (p. 117, data 533). Data a Diego Fernández Amarillo, castellano (11/05/1511): “3 fanegas... para un solar que fagais una casa e para viña por vecino e conquistador que fueste. Digo que pongáis un parral de mill sarmientos junto con vuestro solar" (p. 55, data 202).
} 


\section{CUADRO 1}

LA ORDENANZA MUNICIPAL DE "CASA Y VIÑA"

\begin{tabular}{ccccc}
\hline \multirow{2}{*}{$\begin{array}{c}\text { Número } \\
\text { de cepas }\end{array}$} & \multicolumn{2}{c}{ Marcos } & Superficie $\left.\mathbf{( m}^{2}\right)$ & $\begin{array}{c}\text { Número } \\
\text { de cepas }\end{array}$ \\
\cline { 2 - 3 } Mínimo & Pies $^{*}$ & $\mathbf{m}^{\mathbf{2}}$ & & \\
\hline \multirow{2}{*}{ Máximo } & 800 & $7 \times 7$ & 3,81 & 3.048 \\
& 800 & $8 \times 8$ & 4,97 & 3.976 \\
& 800 & $9 \times 9$ & 6,29 & 5.032 \\
\hline & 5.000 & $7 \times 7$ & 3,81 & 19.050 \\
& 5.000 & $8 \times 8$ & 4,97 & 24.850 \\
& 5.000 & $9 \times 9$ & 6,29 & 31.450 \\
\hline
\end{tabular}

* Un pie equivale a $27,9 \mathrm{~cm}$.

Fuentes: Véanse las notas 8 y 9 .

ordenanza de casa y viña, afectaba a todos los colonos y tenía en cuenta su capacidad financiera. Así, los colonos jornaleros obtuvieron un solar para una casa y un majuelo de 800 sarmientos $^{8}$, y los colonos con capital una casa y un majuelo de 5.000 sarmientos 9 ; es decir, la citada superficie de 2,62 hectáreas.

Interesa comentar el alcance de esta ordenanza. Un majuelo de 800 sarmientos ocupa, según los marcos de plantación de la viticultura insular, de 3.000 a $5.000 \mathrm{~m}^{2}$ (véase el Cuadro 1), y puede ser atendido por la unidad familiar. No ocurría así en el caso de las tierras repartidas a los colonos con capital y obligados a plantar 5.000 sarmientos; la explotación, con una superficie media de 2,62 hectáreas, exigía contratar mano de obra y su producción se dirigía al mercado. Y como éste radicaba en el centro urbano, la mayoría de las datas para plantar vides se localizan en las cercanías de

8 En acuerdo de 13/01/1500, los regidores "mandaron que por quanto ay ordenança que los vecinos de esta ysla puedan hazer pez en los montes della, condicionalmente que hagan que todos hiezen [sic] casas,..., y asy mesmo ser obligado de poner cada uno ochocientos sarmientos, los quales pongan en este presente año...". Y en acuerdo de 6/04/1500 se indica: "Yten ordenaron... que todos los onbres de trabajo que hazen pez, asy a soldada como de qualquier manera, que sean obligados de hazer su casa e viña ni más ni menos que los vecinos, so las penas contenidas, y las casas sean obligados de las hacer desde oy [6 de abril] fasta en todo el mes de mayo primero que vendrá, y ... cerquen las tierras para que se pongan al invierno venidero, so la dicha pena contenida". Citado por Serra (1996), pp. 26 y 28.

9 En 1515, se otorga carta de vecindad al comerciante-banquero catalán Antonio Font "con tal que haga una casa de sesenta pies... una viña de cinco mil cepas y que no la pueda vender en cinco años y que en dos años la plante y fabrique". Citado por Serra y Rosa (1965), p. 98. 


\section{CUADRO 2}

REPARTIMIENTO DE TIERRAS PARA VIÑAS EN TENERIFE, 1499-1514

\begin{tabular}{|c|c|c|c|c|c|c|c|}
\hline \multirow{3}{*}{$\begin{array}{l}\text { Áreas } \\
\text { de } \\
\text { cultivo }\end{array}$} & \multirow{3}{*}{$\begin{array}{c}\text { Número } \\
\text { de } \\
\text { colonos }\end{array}$} & \multicolumn{6}{|c|}{ Superficie (en fanegadas) } \\
\hline & & \multicolumn{2}{|c|}{ Secano } & \multicolumn{2}{|c|}{ Regadío } & \multirow{2}{*}{ Total } & \multirow{2}{*}{ Promedio } \\
\hline & & Fanegadas* & Porcentaje & Fanegadas* & Porcentaje & & \\
\hline La Laguna & 214 & 1.069 & 98,8 & 13 & 1,2 & 1.082 & 5,1 \\
\hline Taoro & 43 & 14 & 6,7 & 196 & 93,3 & 210 & 4,9 \\
\hline Daute & 20 & 42 & 41,6 & 59 & 58,4 & 101 & 5,1 \\
\hline Totales & 277 & 1.125 & 80,8 & 268 & 19,2 & 1.393 & 5,0 \\
\hline
\end{tabular}

* La fanegada de Tenerife equivale a $5.249,49 \mathrm{~m}^{2}$.

Fuentes: Elaboración propia a partir de Serra (1978).

los primeros núcleos urbanos - La Laguna, La Orotava, Garachico, Las Palmas de Gran Canaria y Santa Cruz de La Palma-; es decir, en los "pagos de viñas".

Conocemos con bastante aproximación estos repartimientos en el caso de Tenerife. Su gobernador distribuyó 1.393 fanegadas (731,25 hectáreas), la mayoría de secano, a una media de 2,64 hectáreas por colono (véase el Cuadro 2) ${ }^{10}$. En La Laguna, su primer "pago de viñas" tuvo una superficie de 1.082 fanegadas, a una media de 2,65 hectáreas por colono. Los dos pagos situados en el valle de Taoro ocuparon la parte baja del primitivo casco urbano de La Orotava y de El Realejo y se repartieron 210 fanegadas, la mayoría de secano, a una media de 2,56 hectáreas por colono. Finalmente, en Daute se otorgaron 101 fanegadas, siendo el 58,4 por 100 de regadío, a una media de 2,65 hectáreas por colono.

Por tanto, la política de distribución de tierras para vides atendía a dos estrategias productivas: el autoconsumo y el mercado. Los colonos que poseían capital debían construir en su data una casa y un viñedo de cinco mil cepas, y de ochocientas si tenían la condición de colono trabajador. Y como estas datas para vides se localizaban en las medianías insulares, es decir, por encima de la franja litoral bajo riego destinada a los cañaverales y dominio en su mayor parte de la sacarocracia, la ordenanza

10 Por supuesto, los principales colonos obtuvieron datas de mayor cabida. Así, el gobernador concedió al escribano Miguel Márquez 10,5 hectáreas para viñas porque "venistes de Castilla en compañía de Alonso de las Hijas... y visto ser onbre que trabajáis, ydificáys, ennobleceys la ysla". Citado por Serra (1978), p. 201, data 1.060-18. 


\section{CUADRO 3}

ORIGEN DE LOS VITIVINICULTORES DE TENERIFE, 1500-1513

\begin{tabular}{lccccc}
\hline \multicolumn{1}{c}{ Colonos } & \multicolumn{3}{c}{ Superficie repartida } \\
\hline \multicolumn{1}{c}{ Origen } & Número & Porcentajes & Hectáreas & Porcentajes & Promedio \\
\hline Portugueses & 30 & 38,0 & 86,09 & 36,2 & 2,87 \\
Andaluces & 18 & 22,8 & 61,42 & 25,9 & 3,41 \\
Castellanos $^{\star}$ & 14 & 17,7 & 47,25 & 19,9 & 3,38 \\
Extremeños & 10 & 12,7 & 26,25 & 11,1 & 2,63 \\
Indígenas & 7 & 8,9 & 16,54 & 7,0 & 2,36 \\
\hline Totales & $\mathbf{7 9}$ & $\mathbf{1 0 0 , 0}$ & $\mathbf{2 3 7 , 5 5}$ & $\mathbf{1 0 0 , 0}$ & $\mathbf{3 , 0 1}$ \\
\hline
\end{tabular}

* Procedentes del resto del territorio castellano.

Fuentes: Elaboración propia a partir de Serra (1978).

de casa y viña forjó la construcción de la nueva geografía agraria y humana de las medianías insulares: un hábitat disperso, integrado por familias de pequeños y medianos propietarios, con sus viviendas rodeadas de viñas, huertas y pomares.

\subsection{El colonato vitivinicultor: la aportación luso-andaluza}

Las actas de los repartimientos mencionan al colono y, en algunos casos y con extrema vaguedad, su origen y profesión, pero hemos logrado identificar la procedencia de setenta y nueve, el 28,5 por 100 del total. Destacan en esta pequeña muestra los portugueses, seguidos de los andaluces (véase el Cuadro 3), y las citas a su actividad sugieren que eran vitivinicultores y mercaderes de caldos de las regiones y puertos que comercializaban la oferta vinícola andaluza (la región onubense-gaditana $^{11}$ ) y lusitana (Oporto ${ }^{12}$ y Madeira ${ }^{13}$ ) en los mercados del noroeste europeo en el siglo XV.

Así pues, el constructor de la primera vitivinicultura de la expansión ultramarina de Castilla fue un colonato de origen luso y, en menor medida, extremeño-andaluz. Su

Otte (1996), pp. 120-121.

Martínez Sopena (1996), pp. 71-84.

Vieira (2003), p. 294. 
análisis biográfico revela que se trataba de emprendedores vinculados a la producción y al comercio del vino, integrados en familias extensas con lazos de vecindad, parentesco y dependencia sociolaboral ${ }^{14}$. ¿Qué motivos determinaron su movilidad? Los mercaderes andaluces-extremeños llegaron a las islas como importadores de caldos, pero pronto se percataron de las posibilidades vitivinícolas de la nueva tierra e invirtieron sus ganancias en la creación de esta economía. Por su parte, la movilidad de los lusitanos obedeció principalmente a la oferta colonizadora de la corona castellana.

El reparto de tierra libre y fértil finalizó en Madeira en 1496. A partir de entonces, todo inmigrante que deseara avecindarse en calidad de propietario debía adquirir su fundo en un mercado que no estaba al alcance de todos por el control creciente de toda la tierra por la sacarocracia. Además, si la fertilidad de la isla, debida a sus condiciones naturales y a la juventud de su labor, había compensado la excesiva fiscalidad señorial, las cosas cambiaron a medida que el agotamiento de los suelos convertía la presión fiscal en un obstáculo al crecimiento económico.

La "privación relativa" condiciona la movilidad, y ésta llegó con la colonización de Canarias. El cierre del frente colonizador de Madeira y el alza de la presión fiscal coincidieron con la apertura de otro frente cuyo responsable institucional, la corona castellana, permitió la arribada de toda clase de gentes, redujo la fiscalidad a su mínima expresión, entregó la tierra fértil libre de toda carga y otorgó plena libertad mercantil al colonato. Cierto es que también aquí la sacarocracia privatizó muy pronto la tierra apta para los cañaverales, pero la mayoría de los suelos de Tenerife y La Palma eran más apropiados para las vides, debido al carácter reciente de su edafogénesis.

Aislamos así el otro factor de atracción que intervino en la decisión de movilidad del vitivinicultor madeirense, que explica, al propio tiempo, su ventaja sobre el castellano en esta empresa colonizadora. Aquél tuvo por divisa el progreso tecnológico y una estrategia productiva vinculada al mercado. Procedía del área lusogalaica y, desde mediados del siglo $\mathrm{XV}$, adaptó con éxito la cultura vitivinícola de

14 En el caso extremeño-andaluz, destacan los comerciantes de vinos Juan Méndez y Juan de Regla, el onubense Juan Sánchez de Bollullos y los jerezanos Alonso y Rodrigo de Xerez. En el caso lusitano, sobresalen Fernando de Castro, natural de Castro de Ario (Oporto); construyó su hacienda y un muelle en la caleta que todavía lleva su nombre. El madeirense Ruy Blas fue cura de las partes de Daute, que pobló con inmigrantes lusos y tuvo por capital Icode dos Vinos. Gonzalo Díaz, "maestro de hacer ingenios", llegó de Madeira con su familia y llamó luego a su cuñado Antonio Martíns, que vendió sus bienes y se trasladó con su "mujer, hijos, criados y esclavos", siendo uno de los primeros y principales exportadores de vinos. Afons Velho, originario de Machico (Madeira), vendió su patrimonio y con su mujer, hijos, criados y esclavos creó el núcleo originario de la tercera zona vitivinícola de Tenerife (Acentejo). Las referencias se han tomado de las actas de los repartimientos, editadas por Serra (1978), de los protocolos notariales y de Martínez Galindo (1998). 
la Iberia atlántica y mediterránea al territorio madeirense, elaborando desde entonces un caldo con destino al mercado exterior. Las condiciones edafológicas de Madeira son semejantes a las de Tenerife y La Palma, y similares las prácticas culturales vitivinícolas, aunque con resultados bien diferentes: el clima de estas dos islas es más favorable a la viticultura por el mayor número anual de días de sol y las temperaturas más altas. Por consiguiente, la estrategia vitivinícola desarrollada en Madeira podía trasladarse a Canarias, donde lograría un éxito más notable en términos de productividad, así como de riqueza por la menor fiscalidad.

\section{El mercado interior vinícola}

La primera vitivinicultura de la expansión ultramarina de Castilla contó con los factores necesarios para lograr de inmediato su primer establecimiento. Sus agentes operaban de acuerdo con el estímulo del mercado y, por tanto, el éxito dependía, en primera instancia, de la existencia de un mercado interior vinícola en continuo crecimiento. Para ver este estímulo, precisemos primero la dimensión teórica de la demanda, una magnitud que puede estimarse de manera aproximada a partir del consumo promedio de vino por habitante y año, y de las referencias sobre la población.

El estudio del consumo debe atender a la calidad de los caldos y a las diferencias de género, edad y clase social de sus potenciales consumidores, clasificados, además, en rurales y urbanos y de regiones productoras y consumidoras. Pero es imposible llevar a la práctica esta propuesta metodológica y, en realidad, lo único que sabemos es que el consumo de vino de calidad inferior, baja graduación y "aguado" tendió a generalizarse durante la Baja Edad Media, y que era muy elevado por su aporte calórico y virtudes "terapéuticas" y "antisépticas". Las estimaciones propuestas sugieren de medio a un litro de vino diario por habitante $\left(182,5-365\right.$ litros/año) ${ }^{15}$. Por nuestra parte, apuntamos un consumo anual mínimo de 120 litros entre la población isleña de la primera mitad del siglo XVI por las razones siguientes.

Las referencias sobre la participación del vino en los jornales agrícolas mixtos de este período señalan el pago diario de un cuartillo (1,016 litros) o cuartillo y medio $(1,524)^{16}$. Esta cantidad expresaría el consumo medio de la población activa 


\section{CUADRO 4}

BAUTIZADOS EN DIVERSAS PARROQUIAS CANARIAS, 1520-1579

\begin{tabular}{lrllllllll}
\hline & \multicolumn{3}{c}{ Dos parroquias } & \multicolumn{3}{c}{ Cinco parroquias } & \multicolumn{3}{c}{ Diez parroquias } \\
\hline Decenios & Número & Índice & Tasa & Número & Índice & Tasa & Número & Índice & Tasa \\
\hline $\mathbf{1 5 2 0 - 2 9}$ & 68 & 100 & & & & & & & \\
$\mathbf{1 5 3 0 - 3 9}$ & 82 & 120 & 1,8 & 237 & 100 & & & & \\
$\mathbf{1 5 4 0 - 4 9}$ & 155 & 227 & 6,6 & 365 & 154 & 4,4 & 477 & 100 & \\
$\mathbf{1 5 5 0 - 5 9}$ & 256 & 375 & 5,2 & 414 & 175 & 1,3 & 552 & 116 & 1,5 \\
$\mathbf{1 5 6 0 - 6 9}$ & 216 & 316 & $-1,7$ & 441 & 187 & 0,6 & 601 & 126 & 0,9 \\
$\mathbf{1 5 7 0 - 7 9}$ & 276 & 404 & 2,5 & 525 & 222 & 1,87 & 44 & 156 & 2,2 \\
\hline Fuentes: Archivos parroquiales de Gran Canaria, Tenerife y La Palma, Libros de bautizados de las parroquias de Las \\
\end{tabular}

de la unidad familiar, integrada en el caso isleño por 5,5 miembros $^{17}$; y si suponemos que esta unidad contaba con una media de 1,5 activos, tendríamos un consumo anual de vino por habitante de 108,07-151,71 litros.

Recordemos que la ordenanza de casa y viña exigía a los trabajadores la construcción de su casa y de un majuelo de 800 cepas. Cabe pensar, entonces, que los autores de aquélla estimaron que la producción de estas cepas garantizaba el consumo de la unidad familiar. Y como los rendimientos por cepa valoran dicha producción en 700800 litros ${ }^{18}$, podemos concluir que los autores de la ordenanza estimaron el consumo anual por habitante en 127,3-145,4 litros.

La autoridad local de Tenerife calculó el consumo en los años de desabastecimiento de la capital insular. Así ocurrió en 1522, cuando ordenó a los taberneros que no vendieran más de dos cuartillos de vino (2,032 litros) por persona y día ${ }^{19}$. Esta cantidad expresaría el consumo diario familiar, siendo entonces el consumo anual por habitante de 134,8 litros. En 1552 hubo de nuevo problemas de abastecimiento; el consumo de la ciudad, que en ese año contaba con 5.520 habitantes ${ }^{20}$, se computó en 1.103 pipas (538.043 litros) entre mediados de febrero y principios de noviembre (288 días) ${ }^{21}$, de modo que el consumo medio anual por habitante sería de 123,5 litros.

\footnotetext{
17 Alto coeficiente que se debe a la presencia de esclavos en la unidad familiar. Macías (2005), pp. 67-86.

18 Véase más adelante la discusión sobre los rendimientos.

19 Martínez Galindo (1998), p. 869.

20 Moreno (1979), pp. 411-485.

$21 \quad$ Martínez Galindo (1998), p. 854.
} 


\section{CUADRO 5}

ESTIMACIÓN DEL CONSUMO DE VINO EN LOS CENTROS URBANOS EN 1525 Y 1550

\begin{tabular}{lccccccc}
\hline \multicolumn{1}{c}{ Localidades } & \multicolumn{3}{c}{ Vecindarios } & \multicolumn{2}{c}{ Habitantes } & \multicolumn{2}{c}{ Consumo (hls.) } \\
\hline & Años & Vecinos & Hab. & $\mathbf{1 5 2 5}$ & $\mathbf{1 5 5 0}$ & $\mathbf{1 5 2 5}$ & $\mathbf{1 5 5 0}$ \\
\hline Las Palmas (GC) & 1510 & 500 & 2.750 & 3.594 & 4.761 & $4.312,5$ & $5.713,2$ \\
Telde (GC) & & & & & 1.190 & & $1.428,0$ \\
Gáldar-Guía (GC) & & & & & 1.190 & & $1.428,0$ \\
La Laguna (Tfe) & 1514 & 500 & 2.750 & 3.346 & 5.520 & $4.015,5$ & $6.624,0$ \\
La Orotava (Tfe) & 1517 & 150 & 825 & 952 & 2.575 & $1.141,9$ & $3.090,0$ \\
Icod y Garachico (Tfe) & 1517 & 150 & 825 & 952 & 2.943 & $1.141,9$ & $3.531,6$ \\
Santa Cruz de La Palma & 1517 & 400 & 2.200 & 2.537 & 3.964 & $3.045,0$ & $4.756,8$ \\
\hline Totales & & & $\mathbf{9 . 3 5 0}$ & $\mathbf{1 1 . 3 8 1}$ & $\mathbf{2 2 . 1 4 3}$ & $\mathbf{1 3 . 6 5 6 , 7}$ & $\mathbf{2 6 . 5 7 1 , 6}$ \\
\hline
\end{tabular}

Fuentes: Véanse el Cuadro 4 y las notas 23,25 y 27.

La población anterior al vecindario de 1585 es muy difícil de estimar ${ }^{22}$. Pero las series de bautizados sugieren un modelo demográfico con tasas de crecimiento muy elevadas, especialmente en el caso de Gran Canaria (sus dos principales parroquias), debido, sin duda, a la corriente inmigratoria generada por la acción colonizadora de la agroindustria azucarera (véase el Cuadro 4$)^{23}$. Pues bien, este umbral de crecimiento facilita nuestro análisis de los escasos vecindarios de la primera mitad de la centuria, si bien debe tenerse muy presente el carácter aproximativo de nuestros resultados.

En 1505, la Inquisición computó el contingente indígena en 1.200 familias $^{24}$ (6.000 habitantes) y los primeros vecindarios permiten evaluar la población total de las principales aldeas y áreas agrícolas en unos 9.350 habitantes a mediados del decenio de 1510 (véase el Cuadro 5). Parece entonces verosímil admitir una población próxima a los 16.000 habitantes para todo el archipiélago hacia 1505. La información

22 Sobre este vecindario, véase Macías (2003).

23 Los libros de bautizados del territorio señorial (Lanzarote, Fuerteventura, La Gomera y El Hierro) han desaparecido, pero sabemos que su población fue muy corta debido a la atracción del territorio de realengo, donde, como se aprecia en el Cuadro 4, las tasas de crecimiento de su población son sumamente elevadas. Además, como consecuencia de este crecimiento, las parroquias examinadas se vieron afectadas por la creación de nuevos curatos, habiendo desaparecido sus primeros libros de bautizados.

24 Macías (1992). 


\section{CUADRO 6}

ESTIMACIÓN DEL CONSUMO DE VINO EN 1525 Y 1550 EN LAS ISLAS

\begin{tabular}{lrrrr}
\hline & \multicolumn{2}{c}{1525} & \multicolumn{2}{c}{1550} \\
\hline \multicolumn{1}{c}{ Islas } & Población & Hectolitros & Población & Hectolitros \\
\hline Tenerife & 7.500 & $9.000,0$ & 14.367 & $17.240,0$ \\
Gran Canaria & 8.500 & $10.200,0$ & 6.339 & $7.606,8$ \\
La Palma & 3.863 & $4.635,6$ & 6.084 & $7.300,8$ \\
Lanzarote & 574 & 689,2 & 988 & $1.185,3$ \\
Fuerteventura & 766 & 918,9 & 775 & 929,5 \\
La Gomera & 850 & $1.020,5$ & 1.033 & $1.239,3$ \\
El Hierro & 505 & 606,3 & 1.147 & $1.376,4$ \\
\hline Totales & $\mathbf{2 2 . 5 5 9}$ & $\mathbf{2 7 . 0 7 0 , 4}$ & $\mathbf{3 0 . 7 3 2}$ & $\mathbf{3 6 . 8 7 8 , 1}$ \\
\hline
\end{tabular}

Fuentes: Véanse notas 23, 25 y 27.

demográfica mejora a medida que avanza la centuria, y en 1550 la población total era de 30.732 habitantes (véase el Cuadro 6) ${ }^{25}$.

La magnitud del consumo vinícola mínimo subió de casi dos millones de litros en 1505 a 3,7 millones en 1550; de modo que, a primera vista, parece suficiente estímulo para el desarrollo de una economía vitivinícola ligada al mercado desde la primera fecha. Una conclusión que, sin embargo, queda desdibujada si advertimos que una parte importante de la población no acudía al mercado para adquirir el vino de su mesa, como sugiere la ordenanza de casa y viña, y, por consiguiente, aquellos dos millones de litros de 1505 no expresarían la demanda vinícola vinculada al mercado. Su magnitud sería mucho menor y se circunscribiría a los centros "urbanos", lo cual explicaría la preocupación de la autoridad local por garantizar el abastecimiento de caldos mediante la producción de los pagos de viñas que ordenó crear en sus proximidades.

25 La población de Tenerife, Gran Canaria y La Palma ha sido estimada teniendo en cuenta las tasas de crecimiento de los bautizados, la población que se deduce de una tasa de natalidad del 42 por mil y la población en 1585, así como la expansión azucarera de Gran Canaria en la primera mitad del Quinientos y su crisis en la segunda mitad, y, en el caso de Tenerife, su vitalidad demográfica entre 1525 y 1550 por la expansión vitivinícola. Las poblaciones de Lanzarote, Fuerteventura, La Gomera y El Hierro se han calculado mediante la proporción que representaban en el total de Tenerife, Gran Canaria y La Palma en 1585. Por supuesto, estas estimaciones tienen un valor aproximado. 
Aclaremos, entonces, el consumo mínimo de vino de tales centros "urbanos". En conjunto, tendrían una población próxima a los 8.000 habitantes hacia $1505^{26}$, incrementándose a 11.381 en 1525 y a algo más de 22.000 en 1550 (véase el Cuadro 5) ${ }^{27}$, siendo el consumo vinícola mínimo de 960.000 litros en 1505, 1,3 millones en 1525 y 2,6 en 1550. Pero, de nuevo, no podemos sostener que estas dimensiones del consumo mínimo de vino de los primeros centros "urbanos" expresen la demanda que estimula un desarrollo vitivinícola vinculado al mercado. Estas primeras entidades "urbanas" no eran más que grandes aldeas con una población dedicada fundamentalmente a la actividad agraria ${ }^{28}$, de modo que el autoconsumo primaría sobre el mercado $^{29}$.

Ahora bien, la colonización es un proceso dinámico e interactivo y sus estrategias productivas se mueven en el corto plazo, sobre todo si tenemos en cuenta que aquélla se fundamentó en un modelo agroexportador. En este sentido, debemos advertir dos cuestiones. La primera se refiere a la formación del mercado interior vitivinícola. Su estudio revela, de un lado, la escasez y elevada carestía de los caldos por la ausencia absoluta de una oferta doméstica y, de otro, la "angustiosa sed" de sus potenciales consumidores como consecuencia de aquella escasez y carestía. Cabe, pues, argumentar que buena parte de los dos millones de litros de vino estimados como consumo mínimo en 1505 expresaban en este momento una demanda interior vinícola que se cubría con importaciones, siempre caras y contingentes ${ }^{30}$.

La segunda cuestión se refiere al modelo agroexportador. Sus actores tendieron a concentrar todos los recursos en la estrategia que maximizaba la relación de inter-

Se considera que la población “urbana” en 1505 tenía la misma proporción en el total regional que en 1525.

Las Palmas era la capital regional, con un comercio exterior valorado en 34,5 millones de maravedís. Su serie de bautizados comienza en 1500, pero está afectada por las omisiones selectivas y la creación de nuevos curatos. De ahí que su promedio de 50 bautizados anuales descienda en 1507 a valores en torno a 30 —creación del curato de Teror en 1506 - para subir a 140 en 1514, cuando volvió a caer por la creación de las parroquias de Arucas y Moya. Parece razonable, entonces, fijar su media anual de bautizados en 120 en el decenio 1506-1515. Pues bien, si aplicamos a este número una tasa de natalidad del 42 por mil, la población rondaría los 2.857 habitantes en 1510. Por su parte, la capital de Tenerife, La Laguna, tenía según el obispo Arce más de 500 vecinos en 1515, elevados a 600 en el texto de las peticiones a la Corona de 1517, de modo que parece lógico aceptar la primera cifra. Finalmente, en este texto se indica que la segunda parroquia insular, La Orotava, tenía 150 vecinos y hemos supuesto igual cifra para los dos caseríos de Icod y Garachico, mientras que, en el caso de La Palma, dicho texto señala que se inicia un pueblo, que consideramos su capital, en que hay 400 ó 500 vecinos. Las sinodales de Arce en Caballero (1992), p. 917, y las peticiones de 1517 en Serra y Rosa (1965), pp. 256-257. Así, en 1552 solamente un 35 por 100 de los vecinos de La Laguna vivían en el casco urbano. Moreno (1979), pp. 411-485.

29 Tomemos el ejemplo del trigo. El vecindario de La Laguna de 1552 demuestra que un 49,5 por 100 de la población compraba su pan en la plaza. Moreno (1979), pp. 411-485.

30 Así, el consumo mínimo urbano estimado para 1505 supone la importación de 1.500 botas, y en 1506 un único mercader importó 500 botas desde Cádiz. Morales (1967), p. 334, doc. 275. 
cambio con el exterior: producir azúcares para los ricos europeos. El elevado precio del azúcar pagaba los créditos y las caras y precisas importaciones, entre las que se encontraba el vino. Pero todo modelo agroexportador debe procurar de inmediato cubrir en lo posible y a bajo precio su demanda interior de subsistencias, con el fin de garantizar la competitividad de su oferta agroexportadora; una estrategia que tenía muy presente la sacarocracia, pues sus azúcares debían hacerse un hueco en el mercado internacional desplazando a las ofertas mediterránea y madeirense. De ahí que la autoridad local, dominada por la sacarocracia, hiciera valer su política de abastos, que no era otra que la de sus homólogos municipios castellanos: promovió, como ya hemos visto, el cultivo de la vid, fijó los precios del vino y prohibió su exportación desde la primera vendimia ${ }^{31}$.

Pero entonces ocurrió lo obvio. Esta política de abastos, que en teoría frenaba la expansión del cultivo y encarecía los precios al reducir el estímulo importador, no tuvo ningún efecto ${ }^{32}$, pues la verdadera política la dictaba el mercado. Así lo reconocía el municipio de Gran Canaria, dominado totalmente por la sacarocracia —dado que esta isla era la máxima productora de azúcar-, al establecer su ordenanza concejil en esta materia que "cualquier vezino puede vender el vino que de su cosecha tuviere o cogiere en fruto al precio que quisiere syn pena alguna" ${ }^{\prime 3}$.

Las vides alcanzan su madurez productiva transcurridos los primeros cinco años de majuelo. Por consiguiente, el primer mercado interior vinícola se cubrió en su totalidad con importaciones y sabemos que procedían de la Baja Andalucía ${ }^{34}$. Cabe, además, sostener que estas importaciones persistieron mientras la oferta local fue menos competitiva que la foránea en términos de calidad y cantidad, o bien hasta que la autoridad local con intereses vitivinícolas decidió reservar el mercado interior para su oferta.

Desconocemos el valor del vino importado, pero podemos intuir su elevadísimo precio. La serie de ventas anticipadas de vino nuevo en bodega por los viticultores de Tenerife comienza en 1505, cuando la pipa de la metrología insular ${ }^{35}$ se compró a 95 reales de plata ${ }^{36}$, alcanzando en los años siguientes los 100 reales (véase el Cuadro 12). Y como estos precios son sensiblemente inferiores a los de mercado, pode-

\footnotetext{
$31 \quad$ Serra (1996), p. 42.

32 La tasa del vino se fijó en la primera década del Quinientos en 22-24 maravedís por azumbre, valiendo la pipa 62,9-68,6 reales. Los datos del Cuadro 12 muestran que incluso el precio de las compras anticipadas de caldos superó esta tasa.

33 Morales (1976), p. 92.

34 Otte (1996), p. 120. Véase también Martínez Galindo (1998), pp. 663-705.

35 La pipa de Tenerife tiene 120 azumbres o 480 cuartillos y equivale a 487,68 litros.

36 El real castellano circulaba en Canarias por valor de 42 maravedís entre 1497 y 1520, subiendo a 48 a partir de septiembre de 1521. Sobre este tema, véase Macías (2001).
} 
mos suponer que el vino andaluz se vendía a un precio mínimo de 140 reales por pipa en los años en que la oferta local era inexistente — es decir, antes de 1490 en el caso de Gran Canaria y de 1501 en el de Tenerife y La Palma- o no cubría aún una cuota significativa del consumo interior.

Se trataría, además, de una cotización sometida a bruscas oscilaciones al alza si consideramos el comportamiento del mercado vinícola de la Baja Andalucía. Su demanda creció en virtud de una expansión demográfica cada vez más acelerada desde mediados del siglo XV; los años de escasez y carestía fueron frecuentes, y las autoridades urbanas se vieron obligadas en reiteradas ocasiones a prohibir la extracción de estos bienes y a procurar su compra en el exterior. Por consiguiente, en los años en que hubo desabastecimiento por insuficiente cosecha en la Baja Andalucía, el precio del vino en el mercado insular debió superar los 140 reales por pipa. Veamos un ejemplo. La cosecha vinícola de 1507 fue corta y el precio del vino en el mercado urbano de Sevilla experimentó un incremento del 63,6 por 100 con respecto a sus cotizaciones en los dos años precedentes ${ }^{37}$; pues bien, en un acuerdo del concejo de Tenerife de septiembre de 1508 se denuncia que los vinos importados alcanzaban los 200-240 reales por pipa ${ }^{38}$.

Podemos entonces afirmar que, en los inicios de la colonización, sólo los terratenientes y la aristocracia urbana consumían los caldos importados, y el único vino que podían beber los trabajadores era el incluido en el jornal mixto. En efecto. La primera referencia a las tasas salariales, hacia 1500, atañe al municipio de Gran Canaria. El jornal de los peones sería de real y medio (51 maravedís) sin manutención o un real con ella (comida y bebida $)^{39}$, y recordemos que la bebida consistía en un cuartillo (1,016 litros) o cuartillo y medio de vino (2,032). Admitiendo un precio mínimo del vino andaluz de 140 reales por pipa (4.760 maravedís), su valor en el jornal mixto sería de 10 (1 cuartillo) ó 15 maravedís (1,5 cuartillos); el vino, por tanto, suponía entre el 60 y el 90 por 100 del coste de la manutención (medio real), y del 20 al 30 por 100 del jornal nominal (51 maravedís). De ahí que los peones optaran por el salario mixto y los terratenientes por el nominal, una tesis que confirma la tasa de los jornales de Tenerife en 1504, de 63 maravedís y la comida, "en la que no entraba el vino $^{\prime 40}$. Ahora bien, si consideramos la escasez de mano de obra que caracteriza a todo proceso colonizador, pocos jornaleros se contratarían por un jornal mixto sin vino.

Los precios en Sevilla, expresados en arrobas (16,13 litros) y transformados en pipas de la metrología insular, fueron de 28,5 reales en 1505, 29,3 en 1506 y 45,4 en 1507. Hamilton (1976), p. 337, y Otte (1996), p. 43.

Serra y Rosa (1996), p. 16. Según los ediles, los vinos importados se vendían a dos reales y a setenta maravedís (1,67 reales) el azumbre; como la pipa tiene 120 azumbres, su precio sería 200-240 reales.

Morales (1976), p. 65.

Serra (1996), p. 71. 
Podemos ahora comprender el papel del mercado interior en la construcción de la primera vitivinicultura de la expansión ultramarina de Castilla. Los altos precios del vino importado y el sostenido aumento de su demanda estimularon la génesis y el desarrollo vitivinícola en un territorio insular con favorables condiciones para esta agroindustria y capital humano especializado en la misma. Interesaría, por tanto, precisar en lo posible las cuentas de explotación de las primeras haciendas vitivinícolas, a fin de evaluar con mayor concreción este papel del mercado interior.

\section{La primera hacienda vitivinícola}

No disponemos de libros de contabilidad, y nuestra estimación de los costes y beneficios se fundamenta en datos aislados provenientes de fuentes notariales. Todos los cálculos, en moneda insular mientras no se indique lo contrario, se refieren a la explotación vitivinícola que surgió del proceso colonizador de Tenerife en los años 1505-1510: una data de cinco fanegadas $\left(26.247,45 \mathrm{~m}^{2}\right)$, cedida con la obligación de construir "casa y viña" en un plazo máximo de cinco años.

La primera inversión era la destinada a construir la vivienda. La cal y la teja eran bienes de lujo y la primera morada del colono fue la "casa pajiza", una estructura rectangular de una sola planta, paredes de piedra y barro y cubierta de paja de centeno. Se trata de una vivienda de claro origen galaico-lusitano, presente todavía en Madeira y en Canarias, y hogar de la comunidad campesina hasta los albores del siglo XX. Y aunque es difícil averiguar su coste, las referencias notariales lo evalúan en un mínimo de 3.000 maravedís ${ }^{41}$.

La viticultura isleña empleó siempre mano de obra. Pero toda hacienda contaba con un pequeño establo para la bestia de servicio, el ganado menor y las aves de corral, así como un cuarto para los aperos de labranza; valoramos el coste del establo y de dicho cuarto en un 30 por 100 del valor de la casa pajiza (véase el Cuadro 7).

En cuanto al espacio propiamente vitícola ${ }^{42}$, nuestras estimaciones sugieren que se destinaba a las vides $24.607 \mathrm{~m}^{2}$; una superficie en la que, según los marcos de plantación más comunes, tenían cabida 5.000 sarmientos; recordemos que esta unidad fue también empleada como módulo en los repartos de tierras destinados a "casa y viña".

41 Clavijo (1980), doc. 411. Las compraventas de casas en la capital insular avalan este precio. Así, el de seis casas en 1510 oscila entre 4.200 y 11.000 maravedís, situándose esta última casa en la Calle Real. Véanse docs. $363,430,516,542,545$ y 614 .

42 La sacarocracia reconvirtió sus fincas poco productivas en haciendas vitícolas dividiéndolas en lotes de 8 fanegadas, ocupando 7,5 las vides, con expresa prohibición de sembrar otras plantas, y media fanegada (6,25 por 100 de la superficie total) la vivienda, lagar, bodega, establo, almacén para los aperos, patio y huerta. Hemos supuesto que estos espacios guardaban igual proporción en la explotación tipo. 


\section{CUADRO 7}

CAPITALES INVERTIDOS EN LA CONSTRUCCIÓN DE UNA EXPLOTACIÓN DE 2,5 HECTÁREAS

\begin{tabular}{|c|c|c|}
\hline Conceptos & Maravedís & Porcentajes \\
\hline 1. Vivienda (casa pajiza) & 3.000 & 5,3 \\
\hline 2. Otras dependencias & 900 & 1,6 \\
\hline 3. Desmonte y albarrada & 20.000 & 35,0 \\
\hline 4. Coste de plantación & 5.000 & 8,7 \\
\hline 5. Lagar de dos pipas por lagarada & 2.000 & 6,6 \\
\hline 6. Bodega para 30 envases & 6.000 & 23,4 \\
\hline 7. Envases (15 botas ${ }^{\star}$ y 15 pipas $)$ & 5.376 & 19,4 \\
\hline Totales & 42.276 & 100,0 \\
\hline
\end{tabular}

Las primeras vides ocuparon la franja del barlovento insular poblada de monte bajo y plantas xerófilas, y cabe sostener que muchas parcelas estaban ya en parte roturadas por la comunidad indígena ${ }^{43}$. En todo caso, podemos conocer de manera aproximada el coste de todas las labores de plantación. Dos contratos de 1511, referidos a dos fincas situadas en el mismo término, evalúan el coste de plantar 5.000 sarmientos y de desmonte, arada y cerca en 5.000 y 20.000 maravedís, respectivamente $^{44}$.

Una heredad vitivinícola adquiere su capacidad productiva al quinto año de majuelo, y la construcción del lagar y la bodega podían posponerse hasta entonces. Sin embargo, al tercer año se realizaba la primera vendimia, aunque corta, y las referencias indican que toda heredad contaba con lagar y bodega, ajustándose sus dimensiones a la de la producción. Hay que estimar esta última en el caso de nuestra explotación-tipo para poder calcular los dineros invertidos en el lagar y la bodega.

43 Los indígenas no podían realizar labores profundas por carecer de arados. Macías (1992).

$44 \quad$ El primero establece el pago de 10.000 maravedís por plantar 2.000 sarmientos y cercar una heredad en Tegueste, además de otros 8.000 por las labores de los dos primeros años de majuelo, y el segundo, referido a otra heredad situada en el mismo lugar, de un maravedí por sembrar cada sarmiento. Por consiguiente, el coste de plantar los 2.000 sarmientos en la primera finca sería de 2.000 maravedís, y de 8.000 el de desmontar, arar y levantar la albarrada. Hemos aplicando tales ratios a la explotación de 5.000 sarmientos. Los contratos en Clavijo (1980), p. 247, doc. 858, y p. 336, doc. 1.220. 


\section{CUADRO 8}

ESTIMACIÓN DE LOS RENDIMIENTOS VITÍCOLAS EN EL PRIMER TERCIO DEL SIGLO XVI

\begin{tabular}{|c|c|c|c|c|c|}
\hline \multirow{3}{*}{ Conceptos } & \multirow{3}{*}{ Unidades } & \multicolumn{2}{|c|}{ Explotación A } & \multicolumn{2}{|c|}{ Explotación B } \\
\hline & & \multicolumn{2}{|c|}{ ( 4.000 cepas) } & \multicolumn{2}{|c|}{ (5.000 cepas) } \\
\hline & & $\begin{array}{c}\text { Valores } \\
\text { (maravedís) }\end{array}$ & Origen & $\begin{array}{c}\text { Valores } \\
\text { (maravedís) }\end{array}$ & Origen \\
\hline Superficie & $\mathrm{m}^{2}$ & $19.685,60$ & Estimado de B & $24.607,00$ & Dato real \\
\hline Cosecha sin diezmo & Botas & 12,00 & Dato real & 15,00 & Estimado de $\mathrm{A}$ \\
\hline Cosecha con diezmo & Botas & 13,33 & Dato real & 16,67 & Estimado de $\mathrm{A}$ \\
\hline Producción por cepa & Litros & 1,87 & Dato real & 1,87 & Estimado de $\mathrm{A}$ \\
\hline Rendimientos por ha. & Hectolitros & 37,93 & Estimado & 37,93 & Estimado de $\mathrm{A}$ \\
\hline
\end{tabular}

Fuentes: Véase el texto.

Sabemos que una hacienda de regadío de 4.000 cepas produjo como media anual 7.467 litros de vino en el período 1534-1542, es decir, 1,87 litros por cepa (véase el Cuadro 8$)^{45}$. Como nuestra explotación tiene 5.000 cepas en 2,46 hectáreas, su promedio de producción sería de 16,67 botas de mosto y los rendimientos medios de 37,93 hectolitros por hectárea ${ }^{46}$. Pero estos rendimientos no son representativos, pues las datas para viñas con agua no superaron el 20 por 100 de la superficie vitícola repartida (véase el Cuadro 2). Ahora bien, las heredades mejor atendidas de los siglos posteriores, situadas en los secanos húmedos del barlovento insular, lograban promedios por hectárea de 24,38-29,26 hectolitros, y como el plantío que tratamos se localiza en aquella zona y la viña es joven y fértil la tierra, sus rendimientos no podían ser inferiores a estos últimos promedios.

Calculemos el coste del lagar. Debía elaborar dos botas de vino (960 litros) en cada "lagarada" y su coste en la década de 1510 ascendía a unos a 2.000 maravedís ${ }^{47}$. En cuando a la bodega, encerraría las 15 botas de mosto de producción máxima y las

45 Martínez Galindo (1998), p. 266. El autor emplea la bota de 480 litros y obtiene un rendimiento de 1,44 por cepa. Pero la bota tiene 560 litros y a la cosecha neta debe agregarse el diezmo.

46 Estos rendimientos pueden parecer elevados. Obsérvese, no obstante, que se trata de viñas de riego con un promedio de 2.000 cepas por hectárea de tierra de reciente roturación y con suelo y clima adecuados. Además, las contabilidades de algunas haciendas de regadío del siglo XVIII ofrecen rendimientos medios de 37,16 hectolitros por hectárea.

47 Clavijo (1980), p. 301, doc. 1.073. Media casa con un lagar dentro, situada en la capital insular, se vendió en 1510 por 4.000 maravedís, situándose el valor promedio de las casas urbanas entre 5.000 y 11.000 maravedís, según se indica en la nota 41. El valor del lagar rondaría los 2.000 maravedís. 


\section{CUADRO 9}

ESTIMACIÓN DE LOS COSTES DE EXPLOTACIÓN VITÍCOLAS

\begin{tabular}{|c|c|c|c|c|c|c|}
\hline \multirow[t]{3}{*}{ Labores } & \multirow{2}{*}{\multicolumn{2}{|c|}{$\begin{array}{c}\text { Jornales contratados } \\
\text { por hectárea }\end{array}$}} & \multicolumn{2}{|c|}{$\begin{array}{c}\text { Costes por hectárea } \\
(1505-1520)\end{array}$} & \multirow{2}{*}{\multicolumn{2}{|c|}{$\begin{array}{l}\text { Costes de la } \\
\text { hacienda-tipo } \\
\text { (2,5 hectáreas) }\end{array}$}} \\
\hline & & & \multirow{2}{*}{$\begin{array}{c}\text { Salario } \\
\text { Maravedís }\end{array}$} & \multirow{2}{*}{$\frac{\text { Total }}{\text { Maravedís }}$} & & \\
\hline & Jornales & Porcentajes & & & Maravedís & Porcentajes \\
\hline Cavar & 22 & 36,7 & 63 & 1.386 & 3.465 & 30,2 \\
\hline Podar & 18 & 30,0 & 108 & 1.944 & 4.860 & 42,4 \\
\hline Alzar & 12 & 20,0 & 63 & 756 & 1.890 & 16,5 \\
\hline Vendimiar & 8 & 13,3 & 63 & 504 & 1.260 & 11,0 \\
\hline Total & 60 & 100,0 & & 4.590 & 11.475 & 100,0 \\
\hline
\end{tabular}

Fuentes: Véase el texto

15 pipas destinadas a trasegar el vino, así como los cascos de menor tamaño (barriles) y los recipientes de la vendimia (canastas y cestos). El precio promedio de los 30 cascos y de estos recipientes ofrece pocas dudas ${ }^{48}$, pero el de la bodega debe estimarse considerando que se trata de una instalación donde los caldos, una vez cocidos, eran destinados de inmediato a su venta, que se iniciaba por San Martín (11 de noviembre) y finalizaba en los dos primeros meses del siguiente año. Por tanto, la bodega de nuestra hacienda era muy simple, similar en su construcción a la casa pajiza, y podría calcularse su valor máximo en el doble de ésta (6.000 maravedís).

En resumen, la construcción de la hacienda que caracterizó el proceso colonizador vitivinícola, con una extensión de 2,62 hectáreas y 5.000 cepas de planta, supuso una inversión aproximada de 1.006,6 reales de plata castellanos, a un coste por cepa de 0,20 reales y de 384,2 reales por hectárea. Los cálculos siguientes abordan las cuentas de explotación y sus estimaciones son algo más rigurosas.

Los jornales por hectárea según sus diversas labores (véase el Cuadro 9) ${ }^{49}$ se han tomado de las contabilidades vitivinícolas del siglo XVIII y se han contrastado con

48 Según Martínez Galindo (1998), p. 227, los precios oscilaban entre 4 y 24 reales. Hemos supuesto que el precio mínimo (168 maravedís, dado que un real equivalía a 42 maravedís de moneda canaria antes de 1521) refleja el valor de la pipa, y al importe de las 30 pipas se le ha agregado el valor de dos pipas más, que representan el coste del resto de los recipientes necesarios para la vendimia.

49 Las labores se reducen a tres cavas, dos podas (de invierno y de verano), una alzada — que consiste en elevar mediante horquetas los sarmientos unos $40-50 \mathrm{~cm}$ del suelo una vez formado el fruto- $-\mathrm{y}$ la vendimia, a finales de agosto o principios de septiembre. Macías (2005). 


\section{CUADRO 10}

GASTOS DE EXPLOTACIÓN ESTIMADOS EN LOS AÑOS DE MAJUELO

(maravedís)

\begin{tabular}{llrrrrr}
\hline & & \multicolumn{5}{c}{ Años de majuelo } \\
\hline Gastos & Labores & $\mathbf{1}$ & \multicolumn{1}{c}{$\mathbf{2}$} & $\mathbf{3}$ & $\mathbf{4}$ & $\mathbf{5}$ \\
\hline \multirow{3}{*}{ Vitícolas } & Cavar & 3.465 & 3.465 & 3.465 & 3.465 & 3.465 \\
& Podar & 486 & 486 & 1.944 & 2.916 & 4.860 \\
& Alzar & 189 & 189 & 756 & 1.134 & 1.890 \\
& Vendimiar & & & 630 & 840 & 1.260 \\
\hline Total vitícolas & & 4.140 & 4.140 & 6.795 & 8.355 & 11.475 \\
\hline Enológicos & & & & 2.265 & 2.785 & 3.825 \\
\hline Totales & & 4.140 & $\mathbf{4 . 1 4 0}$ & $\mathbf{9 . 0 6 0}$ & $\mathbf{1 1 . 1 4 0}$ & $\mathbf{1 5 . 3 0 0}$ \\
\hline
\end{tabular}

Fuentes: Véase el texto.

las informaciones de los coetáneos y con las cartillas evaluatorias de los primeros amillaramientos. En cuanto a los jornales, son los fijados por la municipalidad de Gran Canaria en 1500, que hemos considerado constantes a lo largo del período de estudio (1505-1520), si bien puede que los salarios efectivamente pagados fuesen más elevados por la escasez de mano de obra de todo proceso colonizador ${ }^{50}$. Teniendo en cuenta esta posible restricción, el importe de las labores vitícolas anuales ascendería a 4.590 maravedís por hectárea en las viñas de secano, elevándose a 11.475 en el caso de nuestra explotación tipo de 2,62 hectáreas.

En cuanto a los costes enológicos, es difícil detallar su correcto cómputo, pero en las contabilidades vitivinícolas del siglo XVIII representan el 25 por 100 de los costes totales de explotación ${ }^{51}$; por tanto, en nuestra hacienda tipo ascenderían a 3.825 maravedís. Finalmente, debe advertirse que estos gastos se reducen durante los dos primeros años de majuelo a las cavas y a una ligera poda y alzada, incrementándose los gastos en estas dos últimas labores al tercer y cuarto año, cuando se le agrega

\footnotetext{
50 Aunque esta sugerencia no se corresponde con los datos disponibles. En 1510 y 1511, el salario mixto mensual de los peones fijos oscilaba entre 500 y 800 maravedís, manteniéndose en esta banda en 1520-1526, y el municipio de Tenerife fijó en 1523 el salario mixto de los segadores, igualado al de los podadores, en 70 maravedís. Para 1510 y 1511, Clavijo (1980), docs. 555, 743 y 1.054; para 1520-1526, Martínez Galindo (1988), pp. 67-75; el acuerdo municipal de 1523, en Serra y Rosa (1970), p. 204.

$51 \quad$ Macías (1988), pp. 64-65.
} 


\section{CUADRO 11}

GASTOS, INGRESOS Y BENEFICIOS, 1505-1520

(maravedís de las islas)

\begin{tabular}{lccccccc}
\hline & & \multicolumn{5}{c}{ Ingresos } & \multicolumn{3}{c}{ Ingresos } \\
\cline { 3 - 8 } Años & $\begin{array}{c}\text { Gastos } \\
\text { (maravedís) }\end{array}$ & Pipas & $\begin{array}{c}\text { Precios } \\
\text { (mrs/pipa) }\end{array}$ & Maravedís & Maravedís & $\begin{array}{c}\text { Porcentaje } \\
\text { sobre los gastos }\end{array}$ & $\begin{array}{c}\text { Por } \\
\text { hectárea }\end{array}$ \\
\hline $\mathbf{1 5 0 5}$ & 4.140 & & 4.180 & & & & \\
$\mathbf{1 5 0 6}$ & 4.140 & & 3.928 & & & & \\
$\mathbf{1 5 0 7}$ & 9.060 & 4,38 & 4.400 & 19.285 & 1.945 & 47,0 & 742,4 \\
$\mathbf{1 5 0 8}$ & 11.140 & 6,57 & 4.620 & 30.374 & 19.234 & 212,3 & $7.341,3$ \\
$\mathbf{1 5 0 9}$ & 15.300 & 11,75 & 3.300 & 38.763 & 23.463 & 153,4 & $8.955,4$ \\
$\mathbf{1 5 1 0}$ & 15.300 & 11,75 & 3.300 & 38.763 & 23.463 & 153,4 & $8.955,4$ \\
$\mathbf{1 5 1 1}$ & 15.300 & 11,75 & 3.575 & 41.993 & 26.693 & 174,5 & $10.188,4$ \\
$\mathbf{1 5 1 2}$ & 15.300 & 11,75 & 3.713 & 43.609 & 28.309 & 185,0 & $10.804,8$ \\
$\mathbf{1 5 1 3}$ & 15.300 & 11,75 & 2.750 & 32.303 & 17.003 & 111,1 & $6.489,6$ \\
$\mathbf{1 5 1 4}$ & 15.300 & 11,75 & 2.750 & 32.303 & 17.003 & 111,1 & $6.489,6$ \\
$\mathbf{1 5 1 5}$ & 15.300 & 11,75 & 3.163 & 37.148 & 21.848 & 142,8 & $8.339,0$ \\
$\mathbf{1 5 1 6}$ & 15.300 & 11,75 & 3.575 & 41.993 & 26.693 & 174,5 & $10.188,4$ \\
$\mathbf{1 5 1 7}$ & 15.300 & 11,75 & 3.369 & 39.577 & 24.277 & 158,7 & $9.266,1$ \\
$\mathbf{1 5 1 8}$ & 15.300 & 11,75 & 2.626 & 30.849 & 15.549 & 101,6 & $5.934,8$ \\
$\mathbf{1 5 1 9}$ & 15.300 & 11,75 & 2.796 & 32.839 & 17.539 & 114,6 & $6.694,2$ \\
$\mathbf{1 5 2 0}$ & 15.300 & 11,75 & 2.613 & 30.688 & 15.388 & 100,6 & $5.873,1$ \\
\hline
\end{tabular}

Fuentes: Véase el texto.

una primera y corta vendimia, para, finalmente, alcanzar todas las labores su correcto cómputo al quinto año; es decir, cuando el majuelo adquiere plena edad productiva (véase el Cuadro 10).

Los ingresos de explotación son, obviamente, el producto del vino por sus precios. Hemos supuesto que nuestra viña se plantó en enero de 1505 y en agosto de 1507 obtuvo una primera y corta vendimia, que fue plena a partir de agosto de 1509 . El rendimiento medio propuesto (26,8 hectolitros/hectárea) permite estimar el mosto de la primera vendimia sin diezmo y transformado en vino en 4,38 pipas ${ }^{52}$, subiendo a 11,75 pipas en la vendimia de 1509, y hemos considerado como constante este promedio (véase el Cuadro 11).

52 El diezmo se abonaba en mosto y el caldo pierde un 5 por 100 al transformarse en vino. 
En cuanto a los precios, nuestra serie se refiere a las compras anticipadas para hacer frente a los gastos de explotación ${ }^{53}$; por consiguiente, estos adelantos en dinero y mercancías revisten la forma de préstamos sobre futuros y cabe pensar que están gravados con un interés del 10 por $100^{54}$. Por su parte, los vitivinicultores con capital propio para atender todos los gastos de explotación venderían la cosecha libre de toda obligación financiera y hemos supuesto entonces que su precio sería un 10 por 100 más alto que el de venta anticipada (véase el Cuadro 11). No se trata, por consiguiente, de precios de mercado, pues al precio en bodega deben agregarse los costes de transporte y comercialización y el beneficio del tabernero, sin que debamos atender a los impuestos, dado que los insulares no pagaban alcabalas ni sisas. Pero los precios que hemos calculado son los correctos si tenemos en cuenta que los vitivinicultores venden sus caldos en bodega.

Los resultados de nuestra exploración son, sin duda, insuficientes. Ahora bien, sugieren una primera conclusión: los beneficios de las tres primeras vendimias compensaron muy pronto las inversiones en la construcción de la hacienda vitivinícola nacida del proceso colonizador (42.276 maravedís de costes estructurales y 8.258 de costes de explotación en los dos primeros años de majuelo, siendo los beneficios acumulados en las tres primeras vendimias de 59.922). La segunda conclusión que apuntan nuestros datos es la relativa caída de los beneficios a partir de 1512; así, de un promedio de 9.366 maravedís (223 reales castellanos) por hectárea en el trienio $1509-1511$ se pasó a $6.167,4$ (146,8 reales) en 1518-1520. Una tendencia que obedece a la baja de los precios del vino (véase el Gráfico 1) y cuyo significado parece claro. La oferta vinculada al mercado interior había crecido por encima de su demanda, al tiempo que la "angustiosa sed" de los primeros colonos, derivada de la inexistencia de caldos de la tierra, se había reducido por el crecimiento del autoconsumo.

En efecto. Los elevados precios determinaron que el colonato con bajas rentas limitase sus compras de vino importado y procurase de inmediato el plantío de vides para garantizar el autoconsumo de la unidad familiar. Por su parte, los terratenientes propiciaron también el autoconsumo de las unidades productivas para

53 Las fuentes sobre los precios son las actas municipales del Concejo de Tenerife y los registros notariales. En las primeras consta la cotización fijada ocasionalmente en el mes de noviembre, variando al alza cuando se requería aliviar la carestía. Pero las reiteradas denuncias sobre el incumplimiento de las tasas sugieren que su precio era muy inferior al de mercado. Por ello, hemos preferido utilizar las actas notariales. Se trata de compras anticipadas de vino nuevo, de modo que revisten la modalidad de préstamos sobre futuros. Ahora bien, el autor de la serie (Martínez, 1998, pp. 903-904) presenta precios mínimos y máximos, declarando que los primeros son del mosto y del vino joven y los segundos de los vinos añejos. Debería, pues, haber anotado tres series (mosto, vino joven y añejo), dado que el precio del mosto no incluye los costes enológicos, un defecto que hemos resuelto tomando el precio medio. 


\section{GRÁFICO 1}

PRECIOS DEL VINO NUEVO DE PRODUCCIÓN LOCAL, 1505-1550

(reales por pipa)

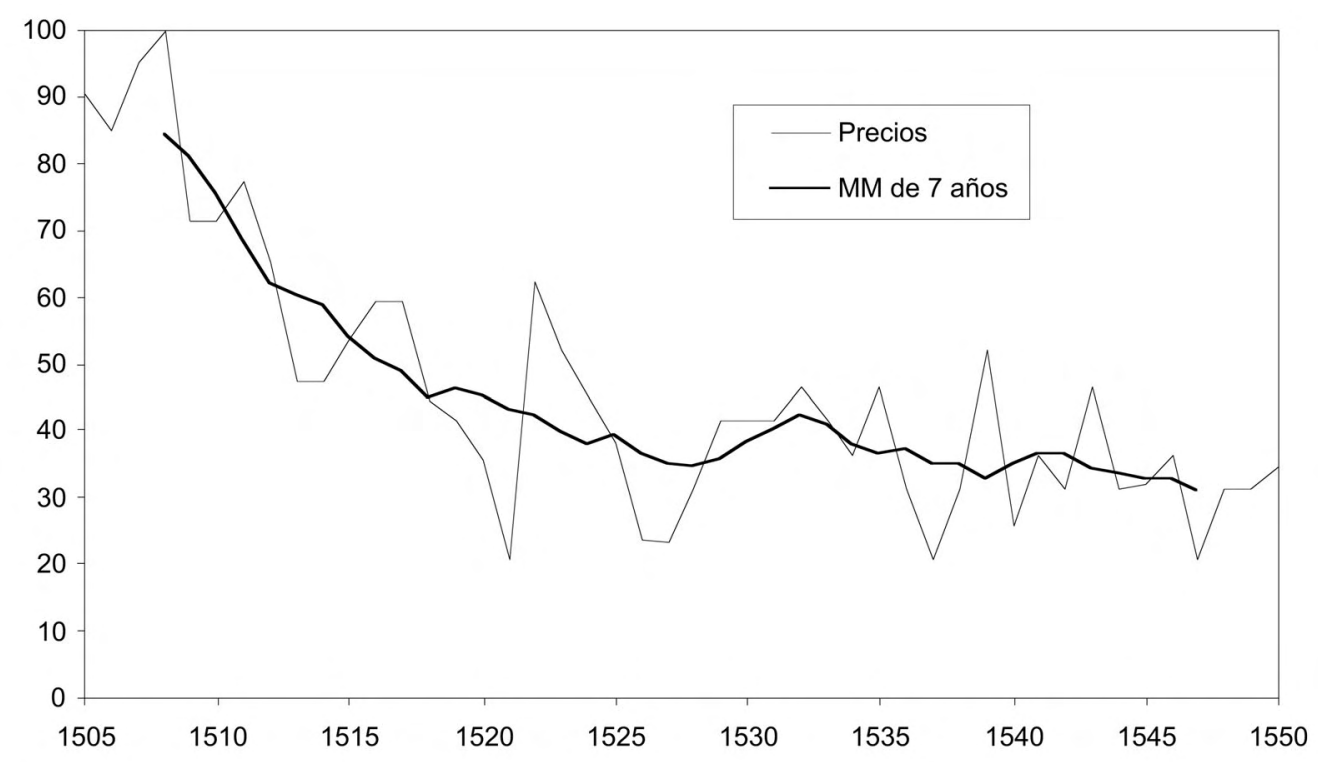

Fuentes: Cuadro 12.

reducir los costes laborales de sus haciendas. Éstos tuvieron, sin duda, problemas de trabajo y de capital para acometer esta estrategia, pues los azúcares absorbían buena parte de sus inversiones y la escasez de mano de obra obligaba a emplear los activos disponibles en las labores con mayor productividad. Pero podían invertir en los viñedos parte de los beneficios azucareros y, además, existían fórmulas contractuales que permitían poner en cultivo estas tierras sin tener que distraer capitales de su opción prioritaria, la agroindustria azucarera.

Tales fórmulas fueron, en primer lugar, la cesión a censo enfitéutico de la merced de tierra obtenida en los repartimientos, exigiendo a cambio un quinto o un cuarto del mosto, una vez descontado el diezmo. Pero los plantíos mediante censo no ejemplifican las inversiones de los terratenientes en el proceso colonizador vitivinícola: aún había tierra libre y fértil para las vides y los colonos preferían obtener una data antes que soportar la presión rentista.

En realidad, el contrato más común fue el de complantación. El propietario de una data convenía con el colono ponerla en cultivo; este último sufragaba toda la inversión y recibía a cambio la titularidad de la mitad de la parcela, haciéndose la 
división una vez realizado el plantío. Por tanto, este contrato permitía al colono con capital propio acceder a la propiedad de las tierras más adecuadas para las vides en manos de terratenientes con interés en su cultivo, pero sin capital para financiarlo. El caso del madeirense Alfonso Bello ilustra esta tesis: llegó a Tenerife en 1498 y firmó un contrato de complantación con el gobernador de la isla, Fernández de Lugo, que poseía en El Sauzal (Tenerife) las mejores tierras para vides, formando de este modo el núcleo inicial de su hacienda, que incrementó luego con nuevas datas y compras $^{55}$.

El caso de Bello permite considerar de nuevo los resultados de nuestro análisis del capital invertido en el modelo colonizador vitivinícola. Quienes llegaron al país interesados en la vitivinicultura y con los dineros precisos para sufragar la totalidad o parte de la inversión que requería la puesta en marcha de su estrategia productiva, tuvieron éxito inmediato. Y lo tuvieron también quienes disponían de capitales procedentes de otra actividad; de ahí la presencia de propietarios urbanos (mercaderes, artesanos, funcionarios) en las concesiones de datas para vides.

Nuestros cálculos sugieren que incluso el colono vitivinicultor sin capital propio pudo afrontar la construcción de su data. Cabe considerar, por último, el caso del colono sin capital propio o ajeno y con data de tierras de secano para el cereal y aptas para las vides. La capitalización de la merced para cumplir con las exigencias del juez repartidor era inmediata si disponía de una yunta de labor para rozar una tierra fértil que al año daba un copioso fruto; de no ser así, podía asociarse con otro colono que tuviera yunta y aperos, y los protocolos notariales del período contienen abundantes ejemplos de semejantes "contratos de compañía" para las sementeras. Las viñas ocuparían las cortinas de estas tierras de pan sembrar, destinándose su caldo a cubrir la demanda de la unidad doméstica. Y como pronto se demostró que la vitivinicultura era más rentable que el cereal, la superficie vitícola se fue ampliando con el dinero obtenido de las ventas de granos en los mercados interior y exterior ${ }^{56}$.

\section{Expansión vinícola y mercado exterior}

Los años de cosechas deficitarias y corto suministro exterior no faltaron; así, el cabildo de Tenerife insistía en el plantío en 1514, para que la pipa valiese mil maravedís "y no como al presente, cuatro mil" 57 . Pero el aumento de la oferta insular resultaba

Martínez Galindo (1998), pp. 541-544.

Vieira (1987).

Serra y Rosa (1965), p. 40. 


\section{CUADRO 12}

PRECIOS DEL VINO NUEVO EN TENERIFE Y SEVILLA, 1505-1550*

(reales por pipa)

\begin{tabular}{|c|c|c|c|c|c|c|c|c|c|c|c|}
\hline Años & Tenerife & Sevilla & Años & Tenerife & Sevilla & Años & Tenerife & Sevilla & Años & Tenerife & Sevilla \\
\hline 1503 & & 35,6 & 1515 & 68,5 & & 1527 & 48,2 & & 1539 & 57,3 & 62,2 \\
\hline 1504 & & & 1516 & 77,4 & & 1528 & 41,7 & & 1540 & 39,1 & \\
\hline 1505 & 90,5 & 28,5 & 1517 & 72,9 & 48,9 & 1529 & 36,5 & & 1541 & 39,1 & \\
\hline 1506 & 85,0 & 29,3 & 1518 & 56,8 & & 1530 & 46,9 & 75,6 & 1542 & 46,9 & 86,7 \\
\hline 1507 & 95,2 & 45,4 & 1519 & 60,5 & 60,5 & 1531 & 67,7 & & 1543 & 54,7 & \\
\hline 1508 & 100,0 & 38,2 & 1520 & 56,5 & & 1532 & 49,5 & 53,4 & 1544 & 44,3 & \\
\hline 1509 & 71,4 & & 1521 & 39,5 & & 1533 & 52,1 & & 1545 & 47,4 & \\
\hline 1510 & 71,4 & & 1522 & 52,1 & & 1534 & 46,9 & & 1546 & 49,5 & \\
\hline 1511 & 77,4 & 30,2 & 1523 & 66,0 & & 1535 & 58,2 & & 1547 & 45,2 & \\
\hline 1512 & 80,4 & & 1524 & 51,2 & & 1536 & 41,7 & & 1548 & 41,7 & 86,3 \\
\hline 1513 & 59,5 & 17,8 & 1525 & 51,1 & & 1537 & 36,5 & 90,7 & 1549 & 36,5 & 134,3 \\
\hline 1514 & 59,5 & & 1526 & 49,6 & & 1538 & 36,5 & & 1550 & 42,6 & \\
\hline
\end{tabular}

* Los precios de Tenerife se refieren a las ventas anticipadas del vino nuevo en bodega y los precios de Sevilla a las compras de los conventos y anticipadas en los años en cursiva.

Fuentes: Para Tenerife, Martínez Galindo (1998), pp. 903-904; sus precios mínimos por pipa (487,68 litros) en maravedís de Canarias se han convertido en reales castellanos como se indica en la nota 38. Para Sevilla, Hamilton (1975), p. 337 y Otte (1996), p. 43; expresados en maravedís por arroba de 16,13 litros, se han pasado a reales por pipa insular.

patente en 1516, cuando los ediles propusieron reservarle el mercado interior ${ }^{58}$, pese a que la propuesta no convenía aún a todos, pues si bien favorecía a los productores, su insuficiencia provocaba las quejas de los consumidores y de la sacarocracia sin intereses vinícolas por el elevado peso del vino en el jornal mixto.

Finalmente, el consenso no fue ya necesario a partir de $1519^{59}$. La oferta local comenzó a cubrir la demanda a un precio inferior a la foránea, sobre todo en la década de 1540, cuando el precio del vino en el mercado de Sevilla (86 reales por pipa) llegó a duplicar el de las compras anticipadas de vino nuevo de producción local (45 reales) (véase el Cuadro 12). En resumen, la oferta isleña era más competitiva que la andaluza destinada al mercado interior desde la década de 1520 debido a la elevada 
productividad de todo viñedo joven, a la preparación tecnológica de sus vitivinicultores y a la pronta presencia de sus vinos en el mercado por la temprana vendimia. Y aunque su calidad era discutible, los consumidores atlánticos estaban dispuestos a comprarlos tan pronto como dejaran de hervir en sus cocederos.

Los vitivinicultores insulares podían entonces aspirar con fundamento a la conquista del mercado exterior, desplazando a una oferta andaluza de vinos de inferior calidad que, con dificultades, lograba atender la primera demanda indiana ${ }^{60}$. Además, podían hacer notar su presencia en los mercados del noroeste europeo mediante la producción de "romanías" 61 y recordemos al respecto que los insulares contaban para este objeto con la red mercantil precisa, es decir, con las ya establecidas en sus lugares de origen o a través de las creadas por las exportaciones azucareras canarias. Parece claro, pues, que el estímulo que necesitaba la vitivinicultura insular hacia 1520 para seguir creciendo no era la reserva del mercado interior, sino el mercado internacional.

\subsection{De los privilegiados a la democracia mercantil}

El comercio exterior isleño se regía por criterios de libertad comercial. Ahora bien, la normativa exportadora regia exigía garantizar el abastecimiento del mercado interior y sólo autorizaba la exportación de una parte del excedente, por lo general un tercio, denominado "tercio de saca", siendo la autoridad local la encargada de conceder la "licencia de saca". Los vitivinicultores palmeros y tinerfeños solicitaron entonces la autorización regia para exportar su "tercio de saca", que llegó en $1525^{62}$.

Pero la licencia del "tercio de saca" tenía poco mérito en un escenario vinculado al comercio internacional. Sus productores tienden a exportar cualquier producto que maximice su valor en términos de bienes y servicios importados. Aplicada esta tesis a un mercado vinícola dominado por la escasez, la conclusión es obvia: los beneficios generados por la venta del vino en el mercado interior eran inferiores a los de su exportación, siempre y cuando concurriesen demandantes foráneos dispuestos a comprar los caldos. Y resulta que esta concurrencia actuó casi desde los inicios de la industria vinícola insular; citemos el avituallamiento de las naves que hacían las rutas atlánticas y los cargamentos de vino y trigo canario adquiridos por Portugal para sus plazas africanas.

\footnotetext{
60 El debate acerca del papel del mercado americano en la expansión de la vitivinicultura andaluza sigue abierto. Véanse Iglesias (1995), pp. 64-66; Pérez (1998), pp. 13-17.

61 Vino blanco seco de alta graduación, obtenido de las variedades torrontés y listán blanco (palomino), y principal oferta de calidad de la vitivinicultura andaluza.

62 Morales (1955), p. 173.
} 
Las denuncias sobre la escasez de caldos por la insuficiente cosecha pueden entonces obedecer a su exportación, que comenzaría desde que hubo interesados en ella, es decir, mucho antes de las "licencias de saca". Los agraciados con las licencias en el caso de Tenerife, la principal productora de vinos, confirman estas sospechas. El municipio autorizaba el "tercio de saca" desde la apertura de las bodegas hasta Navidad, y cerraba luego la exportación con objeto de garantizar el abastecimiento del mercado interior. Pero los regidores gozaban de prioridad en la concesión de las licencias, mientras la oferta de los pequeños viticultores quedaba para el mercado interno. Además, los regidores obtenían sus licencias después de Navidad, cuando sus caldos estaban bien cocidos y con mejor precio en el mercado exterior; y, por último, las licencias se vendían y compraban "porque muchos de los regidores tienen viñas y quieren anticiparse en vender y granjear sus vinos con saca por estar de su mano para ello"63, y "solamente los ricos y poderosos gozan y se aprovechan de la saca y ellos lo sacan todo" 64 .

Los vitivinicultores denunciaron esta corruptela de los privilegiados en 1542. La provisión real de este año otorgó la licencia de un "tercio de saca" a cada vinicultor, pero el problema persistió porque se mantuvo el período de saca y los regidores exportaban sus caldos fuera de este plazo. En 1545 se formuló nueva protesta y se solicitó la libertad de exportación, pues la isla producía un excedente superior a las 9.000 pipas $^{65}$. La aprobación regia llegó en 1549; a partir de entonces todo vitivinicultor pudo embarcar libremente sus caldos.

\subsection{El destino de las exportaciones}

El escenario del comercio exterior canario estaba ya creado hacia 1500, pues a los intercambios con el Mediterráneo, el noroeste europeo y el África occidental se agregaron los embarques a Indias, autorizados desde $1508^{66}$, y los puertos insulares se convirtieron desde esta fecha en almacén de hombres y mercancías para atender la conquista y colonización indianas. Por consiguiente, la normativa exportadora vinícola tuvo por objeto regularizar una exportación que comenzó tiempo atrás y cuyo principal destino era el mercado indiano.

\footnotetext{
Martínez Galindo (1998), p. 712.

Martínez Galindo (1998), p. 725.

Martínez Galindo (1998), p. 724 . El texto indica 400.000 cántaras, que equivalen a 13.369 pipas de Tenerife si tomamos como unidad la cántara de Toledo (16,30 litros). No obstante, creo que se refiere a la producción máxima de la isla, según se desprende de nuestro estudio en preparación sobre los diezmos. Siendo así y admitiendo nuestra estimación del consumo insular (3.535 pipas), el excedente superaría las 9.000 pipas.

66 Peraza (1975), pp. 21-23.
} 


\section{CUADRO 13}

PRINCIPALES DESTINOS DE LAS EXPORTACIONES VINÍCOLAS DE TENERIFE ENTRE 1526 Y 1550* (hectolitros y porcentajes)

\begin{tabular}{|c|c|c|c|c|c|c|c|c|c|c|}
\hline \multirow{3}{*}{$\begin{array}{l}\text { Mercados } \\
\text { Indias }\end{array}$} & \multicolumn{2}{|c|}{ 1526-1535 } & \multicolumn{2}{|c|}{$1536-1540$} & \multicolumn{2}{|c|}{ 1541-1545 } & \multicolumn{2}{|c|}{$1546-1550$} & \multicolumn{2}{|c|}{$1526-1550$} \\
\hline & HIs. & Por 100 & HIs. & Por 100 & Hls. & Por 100 & Hls. $P$ & Por 100 & Hls. $P$ & Por 100 \\
\hline & 96,0 & 21,3 & 384,0 & 36,0 & $1.440,0$ & 30,5 & $5.169,6$ & 47,1 & $7.089,6$ & 41,2 \\
\hline Portugal & 350,0 & 77,6 & 96,0 & 9,0 & $1.372,8$ & 29,1 & 854,4 & 7,8 & $2.673,6$ & 15,5 \\
\hline Flandes & & & 120,0 & 11,3 & $1.008,0$ & 21,3 & 508,8 & 4,6 & $1.636,8$ & 9,5 \\
\hline Islas & & & 273,6 & 25,7 & 696,0 & 14,7 & $1.824,0$ & 16,6 & $2.793,6$ & 16,2 \\
\hline Cabo Verde & & & 192,0 & 18,0 & 57,6 & 1,2 & $1.708,8$ & $3 \quad 15,6$ & $1.958,4$ & 11,4 \\
\hline Castilla & & & & & & & 864,0 & 7,9 & 864,0 & 5,0 \\
\hline Otros & 5,3 & 1,2 & & & 148,8 & 3,2 & 48,0 & 0,4 & 202,1 & 1,2 \\
\hline Totales & 451,7 & 100,0 & $1.065,6$ & 100,0 & $4.723,2$ & 100,0 & $10.977,6$ & 100,0 & $17.218,1$ & 100,0 \\
\hline
\end{tabular}

En efecto. De una muestra parcial de la exportación vinícola del período 15261550 (véase el Cuadro 13), el 41,2 por 100 se envió al mercado colonial, circunscrito sobre todo a las islas de Barlovento. Y aunque los cargadores sevillanos protestaron contra la excepcionalidad isleña a su monopolio, su protesta se debía al contrabando con manufacturas extranjeras y no al embarque de caldos, pues su mayor competitividad frente a los andaluces de igual calidad arruinaba toda oposición a su carga.

He señalado anteriormente las razones que explican esta competitividad y a ellas cabe añadir ahora la franquicia aduanera. Se mantuvo hasta 1537, cuando se decretó el pago del 2,5 por 100 del valor de las mercancías embarcadas. Y aunque en 1543 el almojarifazgo de Indias se reguló en un 5 por 100 para los frutos canarios ${ }^{67}$, los cargados en Sevilla abonaban un 7,5 por 100 de derechos de salida y un 10 por 100 de entrada en el mercado colonial. Por su parte, los consumidores del otro lado

$67 \quad$ Peraza (1975), p. 49. 
del Atlántico reconocían la competitividad del vino isleño y, en general, del almacén portuario insular para cubrir la demanda indiana, frente a la carestía de la oferta sevillana ${ }^{68}$.

El segundo mercado en importancia eran las factorías lusas del África occidental, hacia donde fluía también el excedente de trigo de Tenerife y La Palma. Las exportaciones a las otras islas, especialmente a Gran Canaria, deficitaria en caldos por su prioritaria orientación azucarera, representaban el 16,2 por 100, y cabe pensar que este mercado ocupó un rango más destacado desde principios de la centuria, como sugieren sus compras en el quinquenio 1536-1540.

El noroeste europeo, especialmente Flandes, comenzaba su compra de los caldos de superior calidad. Pero todavía es pronto para hablar de la presencia isleña en este mercado. Hemos de esperar a la segunda mitad del siglo, cuando la cepa malvasía ocupó la franja litoral y permitió a los insulares competir con ventaja con las "romanías". Finalmente, se comprueba la presencia de comerciantes andaluces en los puertos locales para cargar vinos de inferior calidad con destino al mercado indiano.

\section{Conclusiones}

El motor de la colonización fue la agroindustria azucarera. Pero esta economía agroexportadora necesitaba una oferta vinícola doméstica para abastecer la demanda de sus unidades productivas y reducir el elevado coste que suponía la importación de caldos. La autoridad local puso entonces en práctica una política colonizadora vitivinícola mediante la distribución de tierras sin canon alguno y con la obligación de plantarlas de vides. Y como el territorio ofrecía condiciones adecuadas para las vitáceas y esta oferta institucional estuvo abierta a toda clase de gentes y acompañada de ventajas fiscales y mercantiles, concurrieron a estas libertades colonos de origen andaluz y, sobre todo, lusitano, destacando por su aporte tecnológico los madeirenses, aquejados en su hogar por una elevada fiscalidad y por el cierre del frente colonizador. Se trataba, además, de un colonato vinculado a la economía vitivinícola de sus regiones de origen y, por consiguiente, su arribada a las islas tuvo también por objeto la reproducción de sus estrategias productivas.

68 Carta del 10/02/1545 de la Audiencia de Santo Domingo al Consejo de Indias: “De España ya apenas vienen navíos sino de año en año, por donde la pipa de harina mala nos venden a 40 castellanos, la de vino a 50, y peor fuera si no por los socorros de Canarias, a cuyos maestres aquí halagamos y en Sevilla maltratan". Citada por Rumeu (1991), t. I, p. 110. 
El mercado fue, pues, el motor de la colonización vitivinícola y hemos intentando medir su magnitud a partir del consumo de vino por habitante y de las escasas referencias disponibles sobre la población. Los resultados, endebles sin duda por su pobreza empírica, muestran al menos el fuerte crecimiento demográfico de la primera mitad de la centuria y, por tanto, el aumento de igual signo en el consumo, si bien no debemos confundir este consumo con la demanda ligada al mercado, ante la importancia del autoconsumo de las unidades familiares y productivas. Una confusión que, sin embargo, no es posible en los inicios de la colonización; es decir, cuando el territorio carece de una oferta doméstica y debe abastecerse de un vino importado, cuyo elevado precio reduce la competitividad del modelo agroexportador azucarero. De ahí que la primera expansión vitivinícola se debiera a aquella carencia y a los elevados precios del vino importado.

Las tendencias de los precios miden la respuesta de la oferta al estímulo de la demanda en un mercado agobiado por la escasez; de modo que la comprobación empírica de este argumento hubiera bastado para medir el alcance de la primera expansión vitivinícola. No obstante, su correcta medida exigía el análisis de las cuentas de explotación de las haciendas que protagonizaron este proceso; como carecemos de esta información, la hemos estimado, y los resultados, a pesar de su rusticidad teórica-empírica e imposible contraste por la ausencia de similares esfuerzos historiográficos, han permitido mostrar los elevados beneficios vitivinícolas de los primeros años y su caída posterior — pese al aumento de la demanda vinculada al mercado- como consecuencia de la importancia del autoconsumo de las unidades familiares y productivas, a través en este caso de la participación del vino en el salario mixto.

Esta caída de los beneficios vitivinícolas ocurrió a finales de la década de 1510, y los productores reclamaron la reserva del mercado interior para su oferta. Pero esta reserva pierde crédito a partir de 1520, cuando la oferta local comenzó a ser más competitiva que la foránea no sólo en el mercado interior sino en el principal mercado abierto por la expansión ultramarina de los reinos ibéricos. Los vitivinicultores exigieron entonces la liberalización de las exportaciones con el fin de colocar sus caldos en este mercado y en el del noroeste europeo.

En resumen, la primera agroindustria vitivinícola de la expansión ultramarina castellana desempeñó un papel de singular relevancia en la colonización de los espacios insulares donde la agroindustria azucarera no ocupó un lugar destacado en su estructura productiva, y su génesis y desarrollo inicial tuvo como primera fuerza motriz el mercado interior. Una estrategia que se vio luego acelerada cuando, a partir, de 1520, demostró su capacidad de crear riqueza en un modelo agroexportador vinculado al mercado internacional. 


\section{Bibliografía}

AVENTIN PUIG, Mercè (2004): “Ordinacions medievals de viles-mercat catalanes sobre el comerç i consum de vi", en CONGOST I COLOMER, Rosa, y FERRER y ALÒS, Llorent (eds.), Homenatges al Dr. Emil Giralt i Raventos, Barcelona, Universitat de Barcelona, pp. 115-127.

BENNASSAR, Bartolomé (1983): La España del siglo de Oro, Barcelona, Ariel.

BRAUDEL, Fernand (1974): Civilización material y capitalismo, Barcelona, Labor.

CABALLERO MÚJICA, Francisco (1992): Canarias hacia Castilla, Las Palmas de Gran Canaria, Caja Insular de Ahorros.

CLAVIJO HERNÁNDEZ, Fernando (1980): Protocolos del escribano Hernán Guerra, La Laguna, Instituto de Estudios Canarios.

FLANDRIN, Jean-Louis (2004): “La alimentación campesina en una economía de subsistencia”, en FLANDRIN, Jean-Louis, y MONTANARI, Massimo (dirs.), Historia de la alimentación, Gijón, Trea.

HAMILTON, Earl J. (1976): El tesoro americano y la revolución de los precios en España, 1501-1650, Barcelona, Ariel.

IGLESIAS RODRÍGUEZ, Juan J. (1995): “Los siglos modernos: el impacto de la coyuntura americana y la diversificación de mercados", en IGLESIAS RODRÍGUEZ, Juan J. (ed.), Historia y cultura del vino en Andalucía, Sevilla, Universidad de Sevilla, pp. 63-90.

MACÍAS HERNÁNDEZ, Antonio M. (1988): “Explotación directa o medianería en el viñedo canario durante el siglo XVIII. Estrategias para una crisis", Revista de Historia Económica, VI, 1, pp. 43-71.

-(1992): “Expansión europea y demografía aborigen. El ejemplo de Canarias, 14001505", Boletín de la Asociación de Demografía Histórica, IX, 2, pp. 9-45.

-(2000): "La viticultura canaria. Orto y ocaso, 1500-1850", en MALDONADO ROSSO, Javier, y RAMOS SANTANA, Alberto (eds.), Actas del I Encuentro de Historiadores de la vitivinicultura española, Puerto de Santa María, Ayuntamiento del Puerto de Santa María, pp. 319-343.

-(2001): "La construcción de las sociedades insulares. El caso de las Islas Canarias", en FREITAS DE MENESES, Avelino (ed.), Portos, Escalas e Ilhéus no relacionamento entre Occidente e o Oriente, Punta Delgada, Universidad de las Azores, pp. 139-174.

-(2003): "La población de Canarias a finales del siglo XVI. El vecindario de 1585", Anuario de Estudios Atlánticos, 50, pp. 907-953.

-(2005): "El coeficiente de conversión de los vecinos en habitantes (siglos XVIXVII)", en BÉTHENCOURT MASSIEU, Antonio (ed.), Canarias. Hacia una nueva historia, Santa Cruz de Tenerife, Academia Canaria de la Historia, pp. 67-86.

MAGALHAES GODINHO, Vitorino (1982): Os descubrimientos e a economía mundial, Lisboa, Arcàdia. 
MARTÍNEZ GALINDO, Pedro (1988): Protocolos de Rodrigo Fernández (1520-1526), La Laguna, Instituto de Estudios Canarios.

-(1998): La vid y el vino en Tenerife en la primera mitad del siglo XVI, La Laguna, Instituto de Estudios Canarios.

MARTÍNEZ SOPENA, Pascual (1996): “As condiçôes da comercializaçô do vinho no Vale do Douro e na Rioja entre os séculos XII e XV", Douro, 2, pp. 71-84.

MONTANARI, Massimo (1993): El hambre y la abundancia. Historia y cultura de la alimentación en Europa, Barcelona, Crítica.

MORALES PADRÓN, Francisco (1955): El comercio canario-americano (siglos XVI, XVII y XVIII), Sevilla, Escuela de Estudios Hispano-Americanos.

-(1967): "Canarias en el Archivo de Protocolos de Sevilla", Anuario de Estudios Atlánticos, 7, pp. 239-338.

-(1976): Ordenanzas del Concejo de Gran Canaria, Ediciones del Cabildo Insular de Gran Canaria, Las Palmas de Gran Canaria.

MORENO FUENTES, Francisca (1979): "La tazmía de la isla de Tenerife en 1552", Anuario de Estudios Atlánticos, 25, pp. 411-485

OTTE, Enrique (1996): Sevilla y sus mercaderes a fines de la Edad Media, Sevilla, Fundación El Monte.

PERAZA DE AYALA, José (1955): "El contrato agrario y los censos en Canarias", Anuario de Historia del Derecho Español, 25, pp. 257-291.

-(1975): El régimen comercial de Canarias con las Indias en los siglos XVI, XVII y XVIII, Sevilla, Universidad de Sevilla.

PÉREZ CAMACHO, Fernando (1998): “Movilidad vitivinícola entre Andalucía y América a partir del siglo XVI", en RAMOS SANTANA, Alberto, y MALDONADO ROSSO, Javier (ed.), El comercio de vinos y aguardientes andaluces con América (siglos XVI-XX), Cádiz, Universidad de Cádiz, pp. 11-24.

RUMEU DE ARMAS, Antonio (1991): Canarias y el Atlántico. Piraterías y ataques navales, Santa Cruz de Tenerife, Consejería de Cultura del Gobierno de Canarias.

SERRA RÀFOLS, Elías (1978): Las datas de Tenerife (Libro I a IV de datas originales), La Laguna, Instituto de Estudios Canarios.

—(1996): Acuerdos del Cabildo de Tenerife, 1497-1507, La Laguna, Instituto de Estudios Canarios.

SERRA RÀFOLS, Elías, y ROSA OLIVERA, Leopoldo (1965): Acuerdos del Cabildo de Tenerife, 1514-1518, La Laguna, Instituto de Estudios Canarios.

-(1970): Acuerdos del Cabildo de Tenerife, 1518-1525, La Laguna, Instituto de Estudios Canarios.

—(1996): Acuerdos del Cabildo de Tenerife, 1508-1513, La Laguna, Instituto de Estudios Canarios.

VIEIRA, Alberto (1987): O comercio inter-insular nos séculos XV y XVI. Madeira, Açores y Canarias, Funchal, Regiâo Autónoma da Madeira.

-(2003): A vinha e o vinho na história da Madeira. Séculos XV a XX, Funchal, Regiâo Autónoma da Madeira. 